\title{
Erratum to: Universal hydrophilic coating of thermoplastic polymers currently used in microfluidics
}

\author{
Caterina Zilio • Laura Sola • Francesco Damin • \\ Lucia Faggioni $\cdot$ Marcella Chiari
}

Published online: 15 February 2014

(C) Springer Science+Business Media New York 2014

Erratum to: Biomed Microdevices (2014) 16:107-114

DOI 10.1007/s10544-013-9810-8

The original version of this article unfortunately contained a mistake. Tables 1 and 2 are missing in the article and the tables are shown below:

Table 1 Thickness, mass and density of polymer coatings

\begin{tabular}{llll}
\hline Surface Coating & Th $(\mathrm{nm})$ & $\begin{array}{l}\text { Mass } \\
\left(\mathrm{ng} / \mathrm{mm}^{2}\right)\end{array}$ & $\begin{array}{l}\text { Density } \\
\left(\mathrm{g} / \mathrm{cm}^{3}\right)\end{array}$ \\
\hline Poly(DMA-GMA-MAPS) & $9.2+/-0.9$ & $1.6+/-0.02$ & $0.179+/-0.015$ \\
Poly(DMA-NAS-MAPS) & $13.6+/-3.8$ & $1.4+/-0.01$ & $0.105+/-0.03$ \\
\hline
\end{tabular}

Table 2 Thickness, mass and density of the protein layer adsorbed to both coated and uncoated surfaces

\begin{tabular}{llll}
\hline Surface Coating & Th $(\mathrm{nm})$ & $\begin{array}{l}\text { Mass } \\
\left(\mathrm{ng} / \mathrm{mm}^{2}\right)\end{array}$ & $\begin{array}{l}\text { Density } \\
\left(\mathrm{g} / \mathrm{cm}^{3}\right)\end{array}$ \\
\hline Poly(DMA-NAS-MAPS) & $0.4+/-0.02$ & $0.2+/-0.002$ & $0.486+/-0.008$ \\
Uncoated & $5.7+/-0.2$ & $2.2+/-0.03$ & $0.382+/-0.007$ \\
\hline
\end{tabular}

The online version of the original article can be found at http://dx.doi.org/ 10.1007/s10544-013-9810-8.

C. Zilio $\cdot$ L. Sola $\cdot$ F. Damin $\cdot$ L. Faggioni $\cdot$ M. Chiari $(\bowtie)$ Istituto di Chimica del Riconoscimento Molecolare, Consiglio Nazionale delle Ricerche, Via Mario Bianco 9, 20131 Milan, Italy

e-mail: marcella.chiari@icrm.cnr.it 